\title{
A cost-benefit model comparing the California Milk Cell Test and Milk Electrical Resistance Test
}

\begin{tabular}{|c|c|}
\hline \multicolumn{2}{|c|}{$\begin{array}{l}\text { Authors: } \\
\text { Inge-Marie Petzer }{ }^{1} \\
\text { Joanne Karzis }{ }^{1} \\
\text { Isabel A. Meyer }{ }^{1} \\
\text { Theodorus J. van der Schans }{ }^{1}\end{array}$} \\
\hline \multicolumn{2}{|c|}{$\begin{array}{l}\text { Affiliations: } \\
\text { 'Department of Production } \\
\text { Animal Studies, Faculty } \\
\text { of Veterinary Science, } \\
\text { University of Pretoria, } \\
\text { South Africa }\end{array}$} \\
\hline \multicolumn{2}{|c|}{$\begin{array}{l}\text { Correspondence to: } \\
\text { Joanne Karzis }\end{array}$} \\
\hline \multicolumn{2}{|c|}{$\begin{array}{l}\text { Email: } \\
\text { joanne.karzis@up.ac.za }\end{array}$} \\
\hline \multicolumn{2}{|c|}{$\begin{array}{l}\text { Postal address: } \\
\text { Faculty of Veterinary Science, } \\
\text { University of Pretoria, Private } \\
\text { Bag X04, Onderstepoort } \\
\text { 0110, South Africa }\end{array}$} \\
\hline \multicolumn{2}{|c|}{$\begin{array}{l}\text { Dates: } \\
\text { Received: } 14 \text { Nov. } 2012 \\
\text { Accepted: } 30 \text { Mar. } 2013 \\
\text { Published: } 24 \text { Apr. } 2013\end{array}$} \\
\hline \multicolumn{2}{|c|}{$\begin{array}{l}\text { How to cite this article: } \\
\text { Petzer, I.M., Karzis, J., Meyer, } \\
\text { I.A. \& Van der Schans, T.J., } \\
\text { 2013, 'A cost-benefit model } \\
\text { comparing the California } \\
\text { Milk Cell Test and Milk } \\
\text { Electrical Resistance Test', } \\
\text { Onderstepoort Journal of } \\
\text { Veterinary Research 80(1), } \\
\text { Art. \#538, } 6 \text { pages. http:// } \\
\text { dx.doi.org/10.4102/ojvr. } \\
\text { v80i1.538 }\end{array}$} \\
\hline \multicolumn{2}{|c|}{$\begin{array}{l}\text { Copyright: } \\
\text { (C) 2013. The Authors. } \\
\text { Licensee: AOSIS } \\
\text { OpenJournals. This wor } \\
\text { is licensed under the } \\
\text { Creative Commons } \\
\text { Attribution License. }\end{array}$} \\
\hline \multicolumn{2}{|l|}{ Read online: } \\
\hline 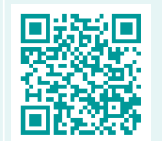 & $\begin{array}{l}\text { Scan this QR } \\
\text { code with your } \\
\text { smart phone or } \\
\text { mobile device } \\
\text { to read online. }\end{array}$ \\
\hline
\end{tabular}

The indirect effects of mastitis treatment are often overlooked in cost-benefit analyses, but it may be beneficial for the dairy industry to consider them. The cost of mastitis treatment may increase when the duration of intra-mammary infections are prolonged due to misdiagnosis of host-adapted mastitis. Laboratory diagnosis of mastitis can be costly and time consuming, therefore cow-side tests such as the California Milk Cell Test (CMCT) and Milk Electrical Resistance (MER) need to be utilised to their full potential. The aim of this study was to determine the relative benefit of using these two tests separately and in parallel. This was done using a partial-budget analysis and a cost-benefit model to estimate the benefits and costs of each respective test and the parallel combination thereof. Quarter milk samples $(n=1860)$ were taken from eight different dairy herds in South Africa. Milk samples were evaluated by means of the CMCT, hand-held MER meter and cyto-microbiological laboratory analysis. After determining the most appropriate cut-off points for the two cow-side tests, the sensitivity and specificity of the CMCT $(S e=1.00, S p=0.66)$, MER $(S e=0.92, S p=0.62)$ and the tests done in parallel $(S e=1.00, S p=0.87)$ were calculated. The input data that were used for partial-budget analysis and in the cost-benefit model were based on South African figures at the time of the study, and on literature. The total estimated financial benefit of correct diagnosis of host-adapted mastitis per cow for the CMCT, MER and the tests done in parallel was R898.73, R518.70 and R1064.67 respectively. This involved taking the expected benefit of a correct test result per cow, the expected cost of an error per cow and the cost of the test into account. The CMCT was shown to be $11 \%$ more beneficial than the MER test, whilst using the tests in parallel was shown to be the most beneficial method for evaluating the mastitis-control programme. Therefore, it is recommended that the combined tests should be used strategically in practice to monitor udder health and promote a pro-active udder health approach when dealing with host-adapted pathogens.

\section{Introduction}

When mastitis, due to host-adapted pathogens Staphylococcus aureus (S. aureus) and Streptococcus agalactiae, (S. agalactiae) is misdiagnosed, the risk of more severe udder parenchymal damage increases. Longer periods of bacterial infection and shedding can create a prolonged window of opportunity for clinical mastitis to develop and for contagious transmission to occur (Lam 1996; Zadocks et al. 2002). In addition to dry-cow treatment, treatment of clinical mastitis forms part of most mastitis-control programmes (Swinkels, Hogeveen \& Zadocks 2005).

Staphylococcus aureus mastitis is highly prevalent in South African dairy herds and is a costly disease (Petzer et al. 2009). According to Goodger and Ferguson 1987 and Zepeda et al. 1998, control of $S$. aureus mastitis through preventive measures, early detection, dry-cow treatment and culling of chronically infected animals can be economically profitable.

Determining the costs specific to a single disease-control programme requires partial budgeting (Smith 1995). In this study, partial-budget analysis was used to determine the relative effects of diagnosing and misdiagnosing true positive and true negative animals. These results were then used to perform a cost-benefit analysis.

In this study, the gold standard used for mastitis diagnosis was defined as a somatic cell count (SCC) of $\geq 400000$ cells $/ \mathrm{mL}$ milk and the presence of mastitogenic bacteria (Petzer et al. 2009). Chronic mastitis, which is associated with a low probability of cure, may be diagnosed by clinical signs. These include palpable tissue changes, a history of repeated clinical mastitis, the presence of bacteria and infection of multiple quarters within a cow (Sol et al. 1997; Sol et al. 2000; Deluyker, Van Oye \& Boucher 2005).

Cow-side tests, such as the California Milk Cell Test (CMCT) and Milk Electrical Resistance (MER) are relatively cost effective and are used in the milking parlour for timeous identification 
of possible udder health problems as part of a mastitiscontrol programme. The International Dairy Federation (IDF) requirement for a cow-side test is for it to have a sensitivity of at least $70 \%$ and a specificity of $99 \%$ (Mein 2010).

The purpose of this study was to determine the most beneficial cut-off points for the diagnosis of mastitis using either of the cow-side tests, when compared to the gold standard. This was done for tests used both separately and in a parallel combination. These cut-off points were then used to calculate sensitivity and specificity. Earlier identification of mastitis using cow-side tests is more beneficial to producers in a mastitis-control programme and could provide the producer with valuable information regarding the early treatment of true mastitis cases. This approach supports proactive udder-health management and may assist in the reduction of the mammary infection rate in herds. Indirect effects of mastitis treatment, such as prevention of clinical mastitis and transmission of infections to other cows are often overlooked in cost-benefit analysis, which may indicate that treatment is more favourable (St Rose et al. 2003; Swinkels et al. 2005).

\section{Methods \\ Sample collection}

The order in which the tests were performed in the parlour was as follows: a strip cup was used to identify possible clinical mastitis cases, after which aseptic quarter milk samples were taken, followed by quarter MER readings and the CMCT.

Quarter milk samples $(n=1860)$ were collected aseptically according to standard procedure (Giesecke, Du Preez \& Petzer 1994) from eight dairies in South Africa. These samples were placed on ice and transported to the Milk Laboratory, Production Animal Studies, Onderstepoort and were analysed within 12 hours of collection. Following aseptic sampling, approximately $5 \mathrm{~mL}$ milk from each quarter was milked into the handheld MER meter. The reading was recorded and this milk was poured into the corresponding cup of the CMCT spatula, in order for the CMCT to be performed. This process was repeated for each quarter that was sampled.

\section{Milk electrical resistance (MER)}

Electrical resistance, the reciprocal of electrical conductivity, was measured in this study. Hand-held MER meters were used to evaluate udder health on a quarter basis. This is in contrast to in-line conductivity that is used in commercial dairies, which is measured at cow level. The hand-held MER meters (Mast-O-Test, Durotec, PO Box 12540, Centralhill, Port Elizabeth 6006, South Africa) read electrical resistance in milli-Ohms per centimeter $(\mathrm{m} \Omega / \mathrm{cm})$. Measures of resistance were categorised into three ordinal levels for data analysis, $<24 \mathrm{~m} \Omega / \mathrm{cm}$ (red light), $24-31 \mathrm{~m} \Omega / \mathrm{cm}$ (orange light) and $>31 \mathrm{~m} \Omega / \mathrm{cm}$ (green light), based on the manufacturer's suggestion. An inter-quarter variation in resistance of $15 \%$ or more indicated possible udder health problems (Mast-O-
Test, Durotec, PO Box 12540, Centralhill, Port Elizabeth 6006, South Africa).

\section{California Milk Cell Test (CMCT)}

The CMCT spatulas were pre-calibrated to help ensure that equal volumes of milk and reagent were used in each test (Schalm, Carroll \& Jain 1971). Excess milk was carefully discarded up to the calibration line, ensuring that the volume of milk left in each cup was equal to the volume of reagent to be added. The milk and reagent were thoroughly mixed whilst carefully studying the viscosity of the mixtures. In this study, the same operator performed the reading according to the description of Schalm et al. 1971. A weak positive $(+)$ was recorded if during swirling, the mixture remained liquid (as with a negative score) and on tilting the paddle, the mixture flowed over the bottom of the cup in a slimy, streaky layer that was clearly visible. A distinct positive $(++)$ was recorded if after the first one to two swirls of the mixture there was already distinct gel formation. Some portions of the distinct positive mixture tended to collect at the centre of the cup, whereas others continued to move around its periphery. Upon stopping the swirling motion, the gel-like mixture levelled out to cover the bottom evenly and on tilting the paddle, the mixture flowed over the bottom of the cup in a distinctly slimy non-uniform mass, possibly of streaky appearance. A strong positive $(+++)$ was recorded if after the first one to two swirls the mixture had already formed a jelly that tended to adhere to the centre of the cup, where it formed a peak and left the periphery of the bottom of the cup exposed. After stopping the swirling motion, the mixture levelled out somewhat on the bottom of the cup, but its surface remained uneven and continued to show a distinct peak in its central region (Schalm et al. 1971).

Acid milk is indicated by the mixture becoming distinctly yellow, with a $\mathrm{pH}$ 5.2. This is very rare and usually indicates fermentation of lactose by bacteria. Alkaline milk is indicated when the reaction causes the mixture to become a deep purple colour, it may be as a result of udder inflammation or indicating that the udder is drying off (Schalm et al. 1971).

\section{Laboratory procedures}

Samples were plated out onto Columbia Agar base plates with 5\% defibrinated bovine blood (Quantum Biotechnologies (Pty) Ltd, Ferndale, South Africa). Test plates were incubated for 24 to 48 hours at $37^{\circ} \mathrm{C} \pm 1^{\circ} \mathrm{C}$. Isolated bacteria were identified in accordance with standard laboratory milk culture methodology based on colony morphology, haemolysis, catalase, $\mathrm{KOH}$ test and Gram staining. Additional tests for bacterial identification included a Strepkit (Latex agglutination test from Quantum Biotechnologies (Pty) Ltd, Ferndale, South Africa), Staphylase Test (Quantum Biotechnologies (Pty) Ltd, Ferndale, South Africa) and the API 20E kit (BioMerieux, PO Box 4328, Honeydew 2040) (Sandholm et al. 1995; Karzis 2005). SCC was determined using the Fossomatic 5000 (Rhine Rhur, PO Box 76167, Wendywood 2144). 


\section{Analysis of data: Sensitivity, Specificity and Determination of Cut-off points}

Data was collected from 1860 aseptic quarter milk samples from eight different dairy herds in South Africa. This data was analysed using a gold standard (criteria used for mastitis positive quarters were: SCC $\geq 400000$ cells $/ \mathrm{mL}$ and bacteria present). Then the most appropriate cut-off point for each test was determined using the gold standard in the statistical programme GenStat ${ }^{\circledR}$ (Payne et al. 2011). Using these cutoff points, the sensitivity and specificity of each of the tests was calculated from the data using Microsoft Excel ${ }^{\circledR} 2003$. The criteria of the gold standard used for disease positive quarters (SCC $\geq 400000$ cells $/ \mathrm{mL}$ ) with bacteria present was taken into account for each test done separately and for both tests done in parallel (Dohoo, Martin \& Stryhm 2003; Petzer et al. 2009).

These findings were used as criteria to determine whether each quarter had an increased SCC using the CMCT, with $(1+, 2+$ and $3+)$ indicating a positive test result and (0) indicating a negative test result. Increased SCC, as well as udder inflammation, are an indication of a possible mastitis case in a mastitis-control programme.

Similarly, the criteria used to evaluate udder inflammation of quarters using MER were as follows: an orange light $(24-31 \mathrm{~m} \Omega / \mathrm{cm})$ and red light $(<24 \mathrm{~m} \Omega / \mathrm{cm})$ indicated a positive test result, whilst a green light $(>31 \mathrm{~m} \Omega / \mathrm{cm})$ indicated a negative test result; the latter being a healthy quarter. Both sets of criteria were calculated in GenStat ${ }^{\circledR}$ using the gold standard (as described above).

The sensitivity and specificity of each of the tests and of the tests in parallel were then inserted into the model as inputs.

\section{Modelling approach}

Partial-budget analysis was used as part of a cost-benefit model. In a cost-benefit model, economic effects for any given scenario are calculated as total revenues weighed against total costs. In this model, the expected cost or benefit of a specific test was calculated. This was done by determining the likelihood that a specific test would predict a false positive, false negative, true positive or true negative result. An expected cost or benefit was associated with each of these outcomes. For example, correctly identifying a true positive result and acting on it would have certain benefits, such as a reduction in the infection rate and a reduction in the decline of milk yield and milk quality. It also has costs associated, such as the cost of treatment and the cost of additional labour. Similarly, incorrectly identifying a true negative result as positive would have costs associated, such as an increase in the loss of milk, an increase in antibiotic residues present in milk and in the bulk tank due to unnecessary treatment, and the cost of treatment.

Partial-budget analysis was used to calculate the relative costs and benefits. In partial-budget analysis, alternatives are compared without calculating a complete budget for each scenario. Instead, only the revenues and costs that are affected by the specific scenario are considered. Total returns were calculated as extra returns plus reduced costs. Total costs were calculated as reduced returns plus extra costs. Both direct and indirect effects of diagnosing and misdiagnosing true positive and true negative animals were taken into account. Biological parameters included the clinical outcome of infection with host adapted pathogens for the affected animal, effects at herd level and contagious transmission for true positives (detected and undetected).

The sensitivity and specificity for each test were used in the cost-benefit model as a basis for determining the expected costs and benefits of each test. The expected value of each cost or benefit was calculated by determining, from the sensitivity and specificity of each test, the positive and negative predictive values of each test. The expected value of a true positive outcome was calculated as the probability of a test identifying a true positive case multiplied by the cost or benefit of that outcome, and similarly for other outcomes. Costs and benefits of correct or incorrect diagnoses were calculated at the cow level (Swinkels et al. 2005).

This model was applied separately for each of the two cow-side tests, as well as for tests used in parallel in order to determine which of the methods were more beneficial, compared to the gold standard criteria used. A comparison of the value of benefits that could be expected from a given test, based on the cost-benefit model, was used to estimate the value of the mastitis-control programme, using the CMCT test, the MER test or a combination thereof (Smith 1995). Model input variables were based on current South African economic conditions and on literature (Keefe 1997; Lactodata 2011). The accuracy of the mastitis- control programme in correct diagnosis of mastitis using the CMCT, MER and the tests in parallel was compared to the gold standard used. Statistical analysis was performed using Microsoft Excel ${ }^{\circledR}$ 2003, by taking the model inputs and prices calculated (see below) into account (Dohoo et al. 2003).

\section{Prices used for model inputs}

Cost of treatment (R45.45) was calculated using the cost of Curaclox LC (Norbrook (ARK AH) PO Box 10698, Centurion 0046), which is commonly used (R15.15 per treatment $x$ three treatments). Milk loss as a result of treatment (R360.86) was calculated using the current milk price at the time of the investigation (R2.97/L) x the average milk production per cow per day (27 L) (Lactodata 2011) $x$ the number of days for which milk was discarded (4.5 days). This was calculated as the sum of the three treatments of Curaclox LC (Norbrook (ARK AH) PO Box 10698, Centurion 0046) at 12 hourly intervals (1.5 days) and the (72h or three day) withdrawal period of the product after final infusion, for which milk was discarded. 
The cost of CMCT test was calculated by calculating the costs of the following:

Mastest reagent per test $=$ price of Mastest per $5 \mathrm{~L}(\mathrm{R} 490) /$ number of tests per $5 \mathrm{~L}(888.33)=0.55$

Number of $6 \mathrm{~mL}$ CMCT tests done per $5 \mathrm{~L}=(1000 \mathrm{~mL} / 6 \mathrm{~mL}$ per test $=166.66$ tests) $\times 5 \mathrm{~L}=888.33$

The cost of the CMCT paddle $=$ R60/number of tests per $5 \mathrm{~L}$ $(\mathrm{R} 888.33)=\mathrm{R} 0.068$

Pump bottle $=\mathrm{R} 30 /$ number of tests per $5 \mathrm{~L}(\mathrm{R} 888.33)=\mathrm{R} 0.034$

Marking pen $=\mathrm{R} 20 /$ number of tests per $5 \mathrm{~L}(\mathrm{R} 888.33)=\mathrm{R} 0.023$

The cost of the CMCT per cow (R2.70) was calculated using the sum of the cost of Mastest reagent per CMCT (R0.55), the cost of the CMCT paddle (R0.068) per test, the cost of the pump bottle (R0.034) per test and the cost of the marking pen (R0.023) used for calibration per test $x$ four quarters per cow.

The cost of the MER test per cow (R5.36) was calculated by the sum of the cost of the handheld Mast-O-Test meter (R2500/1860 tests $=$ R1.34 per test) (Csi-Africa 2011, product specifications) $\mathrm{x}$ four quarters.

\section{Cost-benefit model inputs}

For each test, the cost and benefit of each possible test outcome was calculated. For each possible outcome, positive effects were calculated as benefits and negative effects as costs. For all calculations, the cost of performing the test was included. This model was calculated over the 305 day lactation period for cows infected with host-adapted organisms (Keefe 1997). The following four scenarios were analysed for CMCT, MER and using the tests in parallel.

\section{True positive cases (Sensitivity)}

The benefit of detecting true positive cases of mastitis with cow-side tests was calculated as follows:

(Culling cost (R6000) x 13\% reduced infection rate [19]) + reduced loss of milk (R360.86) - treatment cost (R45.45 x 87\%) [19] $=$ R1101.32 (Table 1)

\section{False negative cases}

The cost of not detecting true positive cases of mastitis by the cow-side tests was calculated as follows:

Estimated loss of milk yield due to sub-clinical mastitis (R360.86) $\mathrm{x} 13 \%$ increased infection rate [19] $=\mathrm{R} 46.91$

\section{True negative cases (Specificity)}

The detection of a quarter with normal udder health by the test is beneficial and has no cost implications.

\section{False positive cases}

The cost of misdiagnosing a healthy quarter with the test was calculated as follows:

The cost of unnecessary treatment (R45.45) + the consequent loss of milk $(\mathrm{R} 360.86)=\mathrm{R} 406.31$

For a given outcome, the expected benefit of the outcome was calculated by multiplying the net benefit with the likelihood of attaining the outcome (i.e. false positive, false negative, true positive, true negative) through the use of this test. The overall cost of the test per cow was subtracted from the expected benefit for all scenarios, since a test is always conducted.

\section{Benefit-cost ratios}

Benefit-cost ratios were calculated as follows (for each test done separately and for both tests combined):

Benefit-cost ratios $=$ expected benefit or (expected cost of error + cost of test).

\section{Results and discussion}

Long periods of infection and bacterial shedding due to misdiagnosis create a prolonged window of opportunity for clinical mastitis to develop and for contagious transmission to occur. In addition to dry-cow treatment, treatment of clinical mastitis is part of most mastitis-control programmes. Indirect effects of mastitis treatment, such as prevention of

TABLE 1: A partial-budget analysis using a cost-benefit model to estimate benefits and costs of the CMCT, MER test done separately and in parallel.

\begin{tabular}{|c|c|c|c|c|c|c|}
\hline \multirow[t]{2}{*}{ Tests } & \multirow{2}{*}{$\begin{array}{l}\text { Cost-benefit Model } \\
\text { Inputs }\end{array}$} & \multirow[t]{2}{*}{ Probability } & \multicolumn{2}{|c|}{ Cost of incorrect diagnosis } & \multicolumn{2}{|c|}{ Benefit of correct diagnosis } \\
\hline & & & $\begin{array}{l}\text { Cost of test } \\
\text { per cow }\end{array}$ & $\begin{array}{l}\text { Expected cost of } \\
\text { error per cow }\end{array}$ & $\begin{array}{l}\text { Benefit of test } \\
\text { per cow }\end{array}$ & $\begin{array}{c}\text { Expected benefit of } \\
\text { test per cow }\end{array}$ \\
\hline \multirow[t]{5}{*}{$\mathrm{CMCT}$} & Sensitivity & 1.00 & - & - & R1101.32 & R1101.32 \\
\hline & False negative & - & R46.91 & - & - & - \\
\hline & Specificity & 0.66 & - & - & R406.31 & $\mathrm{R} 268.17$ \\
\hline & False positive & 0.34 & R406.31 & R138.15 & - & - \\
\hline & Total & - & - & R138.15 & - & R1369.48 \\
\hline \multirow[t]{5}{*}{ MER } & Sensitivity & 0.92 & - & - & R1101.32 & R1013.21 \\
\hline & False negative & 0.08 & R46.91 & R3.75 & - & - \\
\hline & Specificity & 0.62 & - & - & R406.31 & R251.91 \\
\hline & False positive & 0.38 & R406.31 & R154.33 & - & - \\
\hline & Total & - & - & R158.08 & - & R1265.12 \\
\hline \multirow{5}{*}{$\begin{array}{l}\text { CMCT \& MER in } \\
\text { parallel }\end{array}$} & Sensitivity & 1.00 & - & - & R1101.32 & R1101.32 \\
\hline & False negative & - & R46.91 & - & - & - \\
\hline & Specificity & 0.87 & - & - & R406.31 & R353.81 \\
\hline & False positive & 0.13 & R406.31 & R52.50 & - & - \\
\hline & Total & - & - & R52.50 & - & R1455.13 \\
\hline
\end{tabular}


TABLE 2: Summary of the cost-benefit model showing expected costs and benefits and the cost-benefit ratio of the CMCT and MER test done separately and in parallel, taking cost of test per cow into account.

\begin{tabular}{llll}
\hline Summary & CMCT & MER & $\begin{array}{l}\text { Tests done in } \\
\text { parallel }\end{array}$ \\
\hline $\begin{array}{l}\text { Expected benefit of test } \\
\text { per cow }\end{array}$ & R1369.48 & R1265.12 & R1455.13 \\
$\begin{array}{l}\text { Expected cost of error } \\
\text { per cow }\end{array}$ & $-\mathrm{R} 138.15$ & $-\mathrm{R} 158.15$ & $-\mathrm{R} 52.50$ \\
$\begin{array}{l}\text { Cost to conduct test } \\
\text { per cow }\end{array}$ & $-\mathrm{R} 2.70$ & $-\mathrm{R} 5.38$ & $-\mathrm{R} 8.08$ \\
$\begin{array}{l}\text { Cost-benefit ratio } \\
\begin{array}{l}\text { Total expected benefit } \\
\text { of test per cow }\end{array}\end{array}$ & R1228.64 & R1100.29 & R1393.25 \\
\hline
\end{tabular}

CMCT, California Milk Cell Test, MER, Milk Electrical Resistance.

repeated clinical mastitis and transmission to other cows, are often overlooked in cost-benefit analysis, but render a specific treatment as being more favourable (Waage \& Aursjoe 1993; Lam 1996; Hamman \& Zecconi 1998; Zadoks et al. 2002; St Rose et al. 2003; Swinkels et al. 2005).

The sensitivity of CMCT and the parallel combination of CMCT and MER tests are both equal to 1, proving that these methods of diagnosis are equally able to identify true positive animals in the mastitis-control programme, with the expected benefit of test per cow being R1101.32 (Table 1). This is a surprising result, as it was expected that the combination of the two tests (measuring two mastitis indicators) should have had an advantage over one test (measuring only one mastitis indicator). The sensitivity of the MER test of 0.92 (Table 1), show that it is slightly less able to detect true positive animals in the mastitis-control programme than the CMCT test or the tests done in parallel.

The specificity of CMCT, MER test and the tests done in parallel were $0.66,0.62$ and 0.87 respectively (Table 1), indicating that the tests done in parallel were the most beneficial for detecting true negative animals. It also indicated that the CMCT was more beneficial than the MER test for the same purpose. The probability of diagnosing a false negative case using the CMCT and the tests done in parallel were 0 , indicating that these methods were more beneficial in mastitis diagnosis than the MER test $(p=0.08)$ (Table 1$)$, with the cost of error per cow being estimated at R46.91 (Table 1). The probability of a false positive case using the MER test was higher than both that of CMCT on its own and the tests done in parallel, indicating that the MER test was more likely to misdiagnose true negative animals, with the cost of error per cow being estimated at R406.31 (Table 1).

Partial-budget analysis was used in order to estimate benefits and costs to producers of a mastitis-control programme. The part of the enterprise budget affected by mastitis was separated out so that the effects of mastitis were not overshadowed by some other factor or disease (Smith 1995).

A cost-benefit model was used as a method for calculating the cost-benefit ratio, which was an index of the rand value of benefits that could be expected from an investment with a given cost associated (Smith 1995).
The cost-benefit model was also used to calculate the expected costs and benefits of a specific scenario. The sum of the total expected cost of errors per cow (Table 1) and the cost to conduct the test per cow (Table 2) was subtracted from the expected benefits of test per cow for CMCT, MER test. The tests were performed in parallel in order to calculate the total expected benefit of the tests (Table 1).

The CMCT was shown to be more beneficial than the MER test, with a total expected benefit of test per cow of R1228.64 as opposed to that of R1100.29 (Table 2). The most beneficial method for diagnosing mastitis in the mastitis-control programme was using both cow-side tests in parallel, with a total expected benefit of test per cow of R1393.25 (Table 1).

The conclusions made in this study were consistently made on the evaluation of an expected benefit. However, benefitcost ratios were calculated as being 9.72 for CMCT, 7.74 for MER and 24.02 for both tests in parallel (see Table 2).

\section{Conclusions}

The gold standard used for mastitis diagnosis in this study was a SCC $\geq 400000$ cells $/ \mathrm{mL}$ milk and the presence of pathogens (Petzer et al. 2009), which can be both costly and time consuming. A cost-benefit model was used to estimate the accuracy of the mastitis-control programme, by comparing the costs and benefits that arise from using the CMCT, MER test, or both tests in parallel. Misdiagnosis of true mastitis cases by cow-side tests increases the duration of infection when treatment of mastitis is postponed.

When used separately, the expected benefit of CMCT is $11 \%$ more beneficial than the MER test in diagnosing mastitis. The cost-benefit model indicates that, by using the CMCT and MER tests in parallel, the total expected benefit of test per cow is the highest and the expected cost of error per cow the lowest. The total expected benefit of both tests in parallel is $13 \%$ more than that of the MER alone, and $11 \%$ more than that of the CMCT alone.

The sensitivity and specificity for the CMCT test is higher than that of the MER test and similar to that of the two cowside tests used in parallel. The cost-benefit ratio of using both tests in parallel is 2.5 times that of the CMCT test alone, and 3.1 times that of the MER test alone. With all parameters considered, and taking all costs and benefits into account it is clearly beneficial to use both test in parallel.

Further research is recommended to analyse the data collected from in-line EC meters based on cow samples, comparing the accuracy of the results to CMCT results and a combination thereof against the gold standard. Future work with respect to modelling and sensitivity analysis is required in order to assess the extent of reduction in infection rates that should be maintained by control programmes in order to ensure that the process of testing and control of yield has a financially viable outcome. 


\section{Acknowledgements}

The authors thank the dairy producers used for their participation and the staff of the Milk Laboratory, Department of Production Animal Studies, University of Pretoria, Onderstepoort for the analysis of the samples.

\section{Competing interests}

The authors declare that they have no financial or personal relationship(s) that may have inappropriately influenced them in writing this article.

\section{Authors contributions}

J.K. drafted the manuscript and critically revised it, formatted and edited the manuscript, was involved in the data analysis, calculating the sensitivity and specificity, as well as assisting in calculating the cost-benefit model and determining the model inputs for the partial-budget analysis. I.M.P. assisted in collection of aseptic milk samples and performing of cowside tests, assisted with model inputs, reviewing the technical aspects of the manuscript. I.A.M. was involved in calculating the cost-benefit model, doing all the excel calculations, calculating the model inputs and technical editing of the article. T.J.v.d.S. was mainly involved in collecting of aseptic samples and performing of all the cow-side tests in the dairy, as well as in editing the manuscript.

\section{References}

Deluyker, H.A., Van Oye, S.N. \& Boucher, J.F., 2005, 'Factors affecting cure and somatic cell count after pirlimycin treatment of subclinical mastitis in lactating cows', Journal of Dairy Science 88, 604-614. http://dx.doi.org/10.3168/jds.S0022 0302(05)72724-7

Dohoo, I., Martin, W. \& Stryhm, H., 2003, Veterinary epidemiologic research, pp. 100111, Transcontinental Prince Edward Island, Canada.

Giesecke, W.H., Du Preez, J.H. \& Petzer I.M., 1994, Practical Mastitis control in dairy herds, Butterworths, Durban.

Goodger, W.J. \& Ferguson, G., 1987, 'Benefits and costs of a control program for an epizootic of Staphylococcus aureus mastitis', Journal of American Veterinary Medical Association 190, 1284-1287. PMid:3108206
Hamman, J. \& Zecconi, A., 1998, 'Evaluation of the electrical conductivity of milk as a mastitis indicator', Bulletin-FIL-IDF 334, 1-26.

Karzis, J., 2005, 'Intramammary antibiotics in dairy goats: Withdrawal periods and tissue tolerance', MSc thesis, Dept. of Production Animal Studies, University of Pretoria.

Keefe, G.P., 1997, 'Streptococcus agalactiae mastitis: A review', Canadian Veterinary Journal 38(7), 429-437. PMid:9220132, PMCid:1576741

Lactodata, 2011, 'Lactodata Statistics: A Milk SA publication compiled by the Milk Producers' Organisation', vol. 14(1), May 2011, http://www.mpo.co.za/ downloads/LACTO_DATA_MAY_11.pdf

Lam, T.J.G.M., 1996, 'Dynamics of bovine mastitis: A field study in low somatic cell count herds,' PhD dissertation, Utrecht University.

Mein, G., 2010, 'Making sense of new systems for cow-side diagnosis of mastitis,' International All-Stars Mastitis Control Symposium 2010, vol. 2, pp. 26-29.

Payne, R.W., Murray, D.A., Harding, S.A., Baird, D.B. \& Soutar, D.M., 2011, GenStat ${ }^{\circ}$ for Windows $^{T M}$, 14th edn., Introduction, VSN International, UK.

Petzer, I.M., Karzis, J., Watermeyer, J.C., van der Schans, T.J. \& van Reenen R., 2009, 'Trends in udder health and emerging mastitogenic pathogens in South African dairy herds', Journal of the South African Veterinary Association 80(1), 17-22. http://dx.doi.org/10.4102/jsava.v80i1.163, PMid:19653514

Sandholm, M., Honkanen-Buzalski, T., Kaartinen, L. \& Pyörälä, S., 1995, The Bovine Udder and Mastitis, University of Helsinki Faculty of Veterinary medicine, Helsinki.

Schalm, O.W., Carroll, E.J. \& Jain, N.C., 1971, Bovine mastitis, Lea \& Febiger, Philadelphia.

Smith, R.D., 1995, Veterinary Clinical Epidemiology: A problem-orientated approach, 2nd edn., CRC Press, USA.

Sol, J., Sampimon, O.C., Snoep, J.J. \& Sckukken, Y.H., 1997, 'Factors associated with bacteriological cure during lactation after therapy for subclinical mastitis caused by Staphylococcus aureus', Journal of Dairy Science 80, 2803-2808. http://dx.doi. org/10.3168/jds.S0022-0302(97)76243-X

Sol, J., Sampimon, O.C., Barkema, H.W. \& Sckukken, Y.H., 2000, 'Factors associated with cure after therapy for clinical mastitis caused by Staphylococcus aureus' Journal of Dairy Science 83, 278-284. http://dx.doi.org/10.3168/jds.S0022 0302(00)74875-2

St Rose, S.G., Swinkels, J.M., Kremer, W.D., Kruitwagen, C.L. \& Zadocks, R.N., 2003 'Effect of penethamate hydriodide treatment on bacteriological cure, somatic cell count and milk production of cows and quarters with chronic Streptococcus uberis and Streptococcus dysgalactiae', Journal of Dairy Research 72, 75-85.

Swinkels, J.M., Hogeveen, H. \& Zadocks, R.N., 2005, 'A partial model to estimate economic benefits of lactational treatment of subclinical Staphylococcus aureus mastitis', Journal of Dairy Science 88, 4273-4287. http://dx.doi.org/10.3168/jds. S0022-0302(05)73113-1

Waage, S. \& Aursjoe, J., 1993, 'Field trials with a milk conductivity indicator for detection of subclinical mastitis in cows [also incl. California Mastitis test, CMT, AHI milk conductivity indicator', Norsk Veterinaertidsskrift, Organ for Den Norske Veterinaerforening 105(3), 359-362.

Zadoks, R.N., Allore, H.G., Hagenaars, T.J., Barkema, H.W. \& Sckukken, Y.H., 2002, 'A mathematical model of Staphylococcus aureus control in dairy herds', Epidemiology
\& Infection 129, 397-416. http://dx.doi.org/10.1017/S0950268802007483, PMid:12403116, PMCid:2869899

Zepeda, L., Burlow, K.L., Nordlund, K.V., Thomas, C.B., Collins, M.T. \& Goodger, W.J., 1998, 'A linear programming assessment of the profit from strategies to reduce the prevalence of Staphylococcus aureus mastitis', Preventive Veterinary Medicine 33, 183-193. http://dx.doi.org/10.1016/S0167-5877(97)00054-8 